International Journal of Medical Anesthesiology 2020; 3(1): 16-22

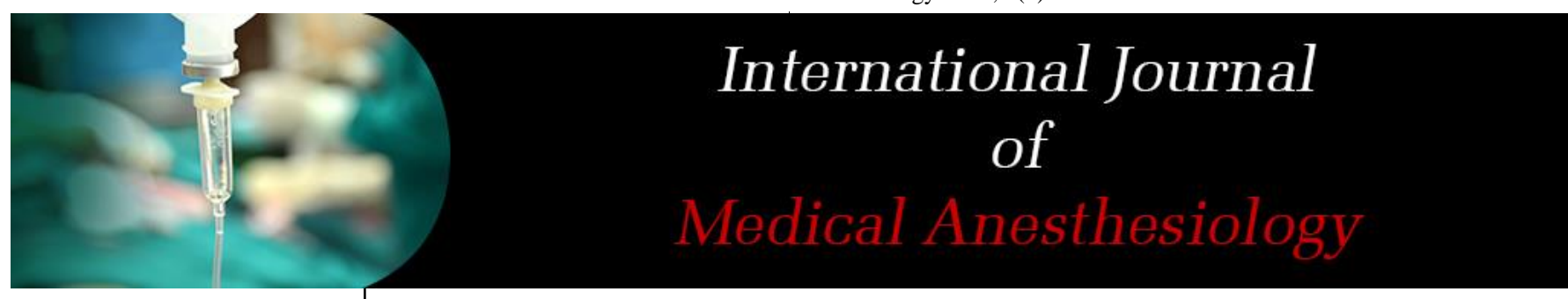

E-ISSN: 2664-3774

P-ISSN: 2664-3766 www.anesthesiologypaper.com IJMA 2020; 3(1): 16-22

Received: 09-11-2019

Accepted: 12-12-2019

Dr Rathna Paramaswamy Professor, Department of Anaesthesiology, Saveetha Medical College Hospital, Chennai, Tamil Nadu, India

Dr S Sabarinath MD Senior Resident, Department of Anaesthesiology, JIPMER, Puducherry, India
Corresponding Author: Dr Rathna Paramaswamy Professor Department of Anaesthesiology, Saveetha Medical College Hospital, Chennai, Tamil Nadu, India

\section{Comparison of effect of $0.5 \%$ ropivacaine with fentanyl versus $0.5 \%$ ropivacaine with buprenorphine in axillary brachial plexus blocks for isolated hand and forearm injuries}

\author{
Dr. Rathna Paramaswamy and Dr. S Sabarinath MD
}

DOI: https://doi.org/10.33545/26643766.2020.v3.i1a.64

\begin{abstract}
Background: Adjuvants with local anaesthetics prolong postoperative analgesia with early ambulation and lesser side effects. Here we compared fentanyl and buprenorphine as adjuvants to $0.5 \%$ ropivacaine in axillary brachial plexus block (ABPB).

Methods: Seventy-eight patients belonging to ASA physical status 1 or 2, aged 20-65 years, undergoing surgery for isolated hand and forearm injuries were divided randomly into three groups. Ultrasound-guided ABPB was performed with $20 \mathrm{ml}$ of ropivacaine $0.5 \%$ and $1 \mathrm{ml}$ of $0.9 \%$ saline (Group C) or $20 \mathrm{ml}$ of ropivacaine $0.5 \%$ and and $50 \mu \mathrm{g}$ fentanyl (Group F) or $20 \mathrm{ml}$ of ropivacaine $0.5 \%$ and $300 \mu \mathrm{g}$ buprenorphine (Group B). The onset and duration of sensory and motor block and analgesia, total dose of rescue analgesic and haemodynamic parameters were measured.

Results: In Group B, the mean time of onset of sensory and motor block was earlier than the other groups. The mean duration of sensory block, motor block and analgesia was longest in Group B followed by Group $\mathrm{F}$ and then Group $\mathrm{C}(P<0.05)$. The mean dose of rescue analgesic was higher in Group C compared to Group F and Group B $(P<0.001)$. The haemodynamic parameters were comparable in the three groups and no adverse effects were seen.

Conclusion: Fentanyl or buprenorphine as adjuvant to $0.5 \%$ ropivacaine in ABPB prolonged the duration of sensory and motor block and post operative analgesia. Ropivacine with buprenorphine had a short onset of sensory and motor block than Ropivacaine with fentanyl and Ropivacaine alone.
\end{abstract}

Keywords: Adjuvant, brachial plexus, buprenorphine, fentanyl, Ropivacaine

\section{Introduction}

The first brachial plexus block was performed by William Halsted in 1885 who applied cocaine to a surgically exposed brachial plexus ${ }^{[1]}$. The first percutaneous supraclavicular block was performed by Diedrich Kulenkampff in Germany in 1911. In the same year Georg Hirshel performed the first percutaneous axillary brachial plexus block ${ }^{[2]}$. It is the most popular peripheral nerve block for hand and forearm surgery. Various approaches of blocking the plexus include the interscalene, supraclavicular, infraclavicular and axillary routes. The interscalene approach is associated with ipsilateral phrenic nerve palsy and is close proximity to the vagus nerve, vertebral artery and has a risk of inadvertent intrathecal or epidural injection. The supraclavicular \& infraclavicular approach has a high incidence of pneumothorax (1-6\%), hemothorax, phrenic nerve block and a possibility of chylothorax with a left-sided block. The ABPB is preferred for procedures below the elbow and has lower risk of complications. The risk of hematoma, nerve injuries and infection is very rare. ${ }^{[3]}$. Ropivacaine is an amino-amide local anesthetic agent with chemical structure, onset and duration of action of brachial plexus block similar to that of bupivacaine ${ }^{[4]}$. Ropivacaine is an S (-) enantiomer of N-(2,6-dimethylphenyl)-1-propyl-2-piperidinecarboxamide. Compared to bupivacaine, it blocks pain transmitting A-delta and $\mathrm{C}$ fibers to a greater extent than A-beta fibers which explains for lesser motor blockade ${ }^{[5]}$. Ropivacaine has been shown to be less cardiotoxic even with accidental intravascular administration and has less motor block and similar duration of sensory analgesia when compared to bupivacaine ${ }^{[6]}$. Opioids administered perineurally act by systemic absorption, spread to central neuraxis, and direct action on peripheral opioid receptors on plexus nerves ${ }^{[7,10]}$. The primary objective of this study was to determine if fentanyl or buprenorphine added to $0.5 \%$ ropivacaine in $\mathrm{ABPB}$ enhanced the block characteristics and post-operative analgesia. 


\section{Material and Methods}

This prospective randomized double-blinded study was done in the Anaesthesia department in a tertiary care Medical College hospital from April 2017 to September 2017. After obtaining Institutional Ethical Committee clearance (EC NO-SMC/IEC/2017/046) and patient's written informed consent, this study was conducted on 78 patients between 20 to 65 years of age belonging to American Society of Anaesthesiologists (ASA) I or II status with isolated hand and forearm surgeries posted for surgery under ABPB. Patients were randomly assigned to one of three groups by a computer-generated random number table. Exclusion criteria was patients with suspected coagulopathy, neuropathies, known allergies to local anaesthetic drugs or adjuvants, pregnant and lactating women and those with body weight less than $50 \mathrm{~kg}$. Sample size was calculated using modification of Cochran's formula as below.

$$
n=\frac{n_{0}}{1+\frac{\left(n_{0}-1\right)}{N}} \quad n_{0}=\frac{Z^{2} p q}{e^{2}}
$$

e- Desired level of precision (margin of error)

p- Estimated proportion of population

$\mathrm{q}=1-\mathrm{p}$

$\mathrm{z}$-Number of standard deviations away from the mean (The mean \pm SD of the duration of post-operative analgesia)

$\mathrm{n}_{0}-$ Cochran's formula sample size

At a $95 \%$ confidence level $(\alpha$ value $=0.05), \mathrm{z}$ score $=1.96$. At a desired power of $90 \%$ with $\mathrm{N}=1000$, e $=19$ and substituting to the above formula, the sample size in each group was 26 .

The enrolled patients were divided randomly into three groups: Group C $(n=26)$, Group $F(n=26)$ and Group B $(n=26)$ ] chosen by computer-generated random selection. The drug solutions were prepared by an anesthesiologist not involved in the study and an experienced anesthesiologist who was blinded performed the axillary block. The data collection was done by a blinded observer. The patients enrolled in the study were examined pre-operatively and the procedure was explained to each patient. In the operating room the patients were connected to a multipara monitor and ECG, non-invasive blood pressure and peripheral oxygen saturation was monitored. An intravenous (IV) cannula was inserted in the adjacent non-operative hand and IV infusion of Ringer's lactate was started. IV midazolam $0.03-0.04 \mathrm{mg} / \mathrm{kg}$ was given and oxygen was administered at $4 \mathrm{~L} / \mathrm{min}$ through a Hudson mask. The patients enrolled in the study were positioned supine with the arm abducted to 90 degrees with forearm supinated and elbow flexed to 90 degrees with the hand either behind or above the head. Under sterile precautions cleaning and draping of the axilla was done. The block was performed using a portable digital colour doppler ultrasound system (Sonoscape model: S8 Exp, Europe S.r.l.) with a high frequency linear array probe $(8-13 \mathrm{MHz})$. The transducer probe was placed transversely on the proximal, medial upper arm. The skin was anaesthetized with $2 \mathrm{ml}$ of $2 \%$ lignocaine prior to introducing the Stimuplex needle. Patients in Group C $(\mathrm{n}=26)$ received $20 \mathrm{ml}$ of $0.5 \%$ ropivacaine plus $1 \mathrm{ml}$ of $0.9 \%$ normal saline, Group F $(n=26)$ received $20 \mathrm{ml}$ of $0.5 \%$ ropivacaine plus $1 \mathrm{ml}$ of fentanyl $(50 \mu \mathrm{g})$ and Group B $(\mathrm{n}=26)$ received $20 \mathrm{ml}$ of $0.5 \%$ ropivacaine plus $1 \mathrm{ml}$ of buprenorphine $(300 \mu \mathrm{g})$ around the brachial plexus through the axillary route. An in-plane approach was used for better needle visualization. The radial, median and ulnar nerves were identified around the pulsatile axillary artery and blocked separately. The musculocutaneous nerve was identified between the biceps and coracobrachialis or within the body of the coracobrachialis and was blocked separately. Inadvertent intravascular injection was avoided by frequent aspiration and visualization on the screen of the ultrasound machine. Inadvertent intraneural injections were also avoided by stopping the injection when the patient complained of pain during injection. The onset and duration of motor block and sensory block, time to first rescue analgesic, pain scoring by Visual Analogue Scale (VAS), heart rate and blood pressure were recorded for each patient. Sensory and motor blockade were assessed at every two minutes interval after completion of injection and then after the end of surgery until first 24 hours till the block had completely worn off. Heart rate and blood pressure was noted at every ten minutes interval throughout surgery. The patients were monitored in the post anesthesia care unit for the first 24 hours. Following completion of the local anesthetic injection, the sensory block was evaluated by Hollmen scale as:

- Normal sensation of pinprick

- Pinprick felt as sharp pointed but weaker compared with same area in the other upper limb

- Pinprick recognized as touch with blunt object

- No perception of pinprick.

The onset time of the sensory block was taken as the time interval in minutes from injection of the local anesthetic till a Hollmen score of 2, while the time for the complete sensory block was taken from injection of the local anesthetic till a Hollmen score of 4 . The total duration of the sensory block was taken as the duration of the time in minutes from the time of complete sensory block till the time when the Hollmen score less than 4 was reached. Motor block was monitored by thumb adduction (ulnar nerve), thumb abduction (radial nerve), thumb opposition (median nerve) and flexion of elbow and pronation of forearm (musculocutaneous nerve) using a modified Bromage Scale for the upper extremity as

1. Normal motor function with full flexion and extension of elbow, wrist, and fingers.

2. Decreased motor strength with ability to move the fingers only.

3. Complete motor block with inability to move the fingers.

4. Unable to move the arm, elbow or fingers.

Onset of motor blockade was considered as the time interval in minutes from injection of the local anaesthetic till when there was Grade-1 motor blockade. The total duration of the motor block was taken as the duration of the time in minutes between the times to complete motor block till normal motor function (Grade-0). Pain was assessed by using the VAS in which a score of 0 indicates no pain and a score of 10 indicates worst pain. The VAS measurements were obtained every three hours post-operatively at 3, $6,9,12,15,18,21$ and 24 hours. Rescue analgesic in the form of slow IV bolus of $50 \mathrm{mg}$ of tramadol was administered at 
the VAS score of 4. Time to first rescue analgesic and the total analgesic given to each patient during the first 24 hours post-operative period were recorded. The occurrence of adverse effects like hypotension, nausea and vomiting was also monitored.

\section{Statistical analysis}

Statistical analysis was performed by SPSS for Windows, version 17.0 (SPSS Inc, Chicago, Illinois, USA). Since the study had three groups, the following statistics were done.One way ANOVA was used for multiple comparisons among the groups and Chi-square analysis was used to compare demographic characteristics (qualitative variables). Interval data was expressed as mean and standard deviation. Pain levels according to the VAS were analyzed by Friedman test and intergroup comparison by KruskallWallis test followed by the Dunn test in case of difference among the groups. Confidence level was set at $95 \%$ and a pvalue $<0.05$ was considered as statistically significant and a $\mathrm{P}<0.001$ as highly significant. For the analysis of quantitative variables student's paired t-test was used.

\section{Results}

Eighty-five patients with isolated hand and forearm injuries were randomized into three groups. Seven patients with patchy block were excluded from the study as shown in the consort diagram [Fig-1]. In the patients with patchy blocks, general anaesthesia was given. Demographic parameters such as age and sex wise distribution of the participants and duration of surgery were comparable in the three groups [Table-1]. The onset of sensory block preceded the onset of motor block. The average time of onset of sensory block was $5.76 \pm 1.8 \mathrm{~min}$ in Group C, $4.52 \pm 1.53 \mathrm{~min}$ in Group F and $3 \pm 0.81 \mathrm{~min}$ in Group B $(\mathrm{P}<0.0001)$. The average time of onset of motor block was $7.68 \pm 2.3 \mathrm{~min}$ in Group C, 6.2 $\pm 2.14 \mathrm{~min}$ in Group F and $4.56 \pm 1.71 \mathrm{~min}$ in Group B $(P<$ 0.0001 ) [Table $-2 /$ Fig-2]. In group B the time of onset of sensory and motor block was earlier than the other groups and was statistically significant $(P<0.0001)$. The mean duration of sensory block was $525.2 \pm 36.64$ min in Group C, $540.8 \pm 44.8 \mathrm{~min}$ in Group F and $680.4 \pm 40.1 \mathrm{~min}$ in Group B. This was clinically and statistically significant (P $<0.001)$. The mean duration of motor block was $404.4 \pm$ $17.09 \mathrm{~min}$ in group C, $437.2 \pm 44.8 \mathrm{~min}$ in Group F and $535.2 \pm 34.3 \mathrm{~min}$ in group $\mathrm{B}$. This was clinically and statistically significant $(\mathrm{P}<0.001)$ [Table $-2 /$ Fig-3]. The time to rescue analgesia and the total dose of rescue analgesic was compared between the groups by Post-Hoc pair wise comparison to find out the significance. The mean total duration of analgesia measured by time to first rescue analgesic was $619.6 \pm 57.75 \mathrm{~min}$ in Group C, $666.4 \pm$ $107.03 \mathrm{~min}$ in Group F and $815 \pm 119.9 \mathrm{~min}$ in Group B (P $<0.0001)$. The mean total dose of rescue analgesic (tramadol)received during the first 24-hour post-operative period was $75 \pm 24.5 \mathrm{mg}$ in Group C, $60.75 \pm 24.7 \mathrm{mg}$ in Group F and $50 \pm 20.2 \mathrm{mg}$ in Group B. This was clinically and statistically significant $(\mathrm{P}<0.0001)$. Heart rate $(\mathrm{HR})$ and mean arterial pressure (MAP) was recorded from the time of onset of block up to three hours. Heart rate measured at all intervals was within the same range among the three groups. [Table-3/ Fig -4]. The MAP was significantly lower in Groups $\mathrm{R}$ and Group B up to 20 minutes $(\mathrm{P}<0.05)$ and afterwards the MAP observed up to 180 minutes were within the same range among the three groups and were found to be not significant [Table-4/Fig 5]. No side effects like sedation, hypotension, bradycardia, nausea and vomiting were seen in any patient.

Table 1: Demographic characteristics of the three groups.

\begin{tabular}{|c|c|c|c|}
\hline Patient parameters & $\begin{array}{c}\text { Group } \\
\text { C(n=26) } \\
\text { Mean } \pm \text { SD }\end{array}$ & $\begin{array}{c}\text { Group F(n=26) } \\
\text { Mean } \pm \text { SD }\end{array}$ & $\begin{array}{c}\text { Group B(n=26) } \\
\text { Mean } \pm \text { SD }\end{array}$ \\
\hline Age (years) & $29.2 \pm 9.05$ & $30.88 \pm 8.02$ & $27.96 \pm 5.53$ \\
\hline Weight $(\mathrm{kg})$ & $65.20 \pm 13.20$ & $62.34 \pm 23.22$ & $60.34 \pm 24.22$ \\
\hline Height(cm) & $159 \pm 23.89$ & $161 \pm 27.45$ & $157.21 \pm 20.27$ \\
\hline Sex(male/female) & $24 / 2$ & $23 / 3$ & $19 / 7$ \\
\hline Duration of surgery(min) & $123.6 \pm 38.1$ & $108.3 \pm 30.02$ & $103.5 \pm 23.9$ \\
\hline
\end{tabular}

Table 2: Block characteristics of the three groups.

\begin{tabular}{|c|c|c|c|c|}
\hline Parameters & Group R(Mean \pm SD) & Group F (Mean \pm SD) & Group B (Mean \pm SD) & p value \\
\hline Onset of sensory block (min) & $5.76 \pm 1.8$ & $4.52 \pm 1.53$ & $3.0 \pm 0.81$ & $\mathrm{p}<0.00001$ \\
\hline Onset of motor block (min) & $7.68 \pm 2.3$ & $6.2 \pm 2.14$ & $4.56 \pm 1.71$ & $\mathrm{p}<0.00001$ \\
\hline Duration of sensory block (min) & $525.2 \pm 36.64$ & $540.8 \pm 44.8$ & $680.4 \pm 40.1$ & $\mathrm{p}<0.00001$ \\
\hline Duration of motor block (min) & $404.4 \pm 17.09$ & $437.2 \pm 44.8$ & $535.2 \pm 34.3$ & $\mathrm{p}<0.00001$ \\
\hline Time to rescue analgesic (mins) & $619.6 \pm 57.75$ & $666.4 \pm 107.03$ & $815 \pm 119.9$ & $\mathrm{p}<.00001$ \\
\hline Total dose of rescue analgesic (m) & $75 \pm 24.5$ & $60.75 \pm 24.7$ & $50 \pm 20.2$ & $\mathrm{p}<0.0013$ \\
\hline
\end{tabular}

Table 3: Heart rate variations in the three groups.

\begin{tabular}{|c|c|c|c|c|}
\hline $\begin{array}{c}\text { Time intervals in } \\
\text { minutes }\end{array}$ & $\begin{array}{c}\text { Heart rate in Group R } \\
\text { Mean } \pm \text { SD }\end{array}$ & $\begin{array}{c}\text { Heart rate in Group F } \\
\text { Mean } \pm \text { SD }\end{array}$ & $\begin{array}{c}\text { Heart rate in Group } \\
\text { B Mean } \pm \text { SD }\end{array}$ & p value \\
\hline 0 & $89.36 \pm 11.14$ & $88.4 \pm 7.26$ & $96.08 \pm 7.97$ & $0.0062^{*}$ \\
\hline 10 & $87.68 \pm 10.54$ & $85.88 \pm 9.39$ & $93.6 \pm 9.2$ & $0.0163^{*}$ \\
\hline 20 & $84.48 \pm 8.9$ & $81.92 \pm 8.9$ & $87.76 \pm 8.5$ & $0.0673^{\#}$ \\
\hline 30 & $83.12 \pm 11.04$ & $78.72 \pm 5.7$ & $84.4 \pm 4.65$ & $0.0276^{*}$ \\
\hline 40 & $82.8 \pm 9.2$ & $77.36 \pm 6.8$ & $84 \pm 4.8$ & $0.0036^{*}$ \\
\hline 50 & $82.24 \pm 7.56$ & $78.4 \pm 6.24$ & $83.6 \pm 4.08$ & $0.0106^{*}$ \\
\hline 60 & $80.24 \pm 9.13$ & $77.96 \pm 4.8$ & $84.64 \pm 4.15$ & $0.0017^{*}$ \\
\hline 70 & $76.68 \pm 7.56$ & $76.92 \pm 5.36$ & $83.04 \pm 5.97$ & $0.0046^{*}$ \\
\hline 80 & $81.2 \pm 6.9$ & $77.32 \pm 3.62$ & $83.04 \pm 5.3$ & $0.0015^{*}$ \\
\hline 90 & $80.32 \pm 8.07$ & $79.04 \pm 4.28$ & $84.24 \pm 5.46$ & $0.010^{*}$ \\
\hline 100 & $81.36 \pm 9.65$ & $80.44 \pm 4.89$ & $83.64 \pm 6.71$ & $0.291^{\#}$ \\
\hline 110 & $80.96 \pm 8.02$ & $79.52 \pm 6.03$ & $84.72 \pm 7.7$ & $0.04^{*}$ \\
\hline 120 & $81.84 \pm 7.61$ & $78.72 \pm 6.9$ & $83.92 \pm 5.8$ & $0.03^{*}$ \\
\hline 130 & $81.04 \pm 9.25$ & $79.52 \pm 6.8$ & $84.04 \pm 4.7$ & $0.083^{\#}$ \\
\hline
\end{tabular}




\begin{tabular}{|c|c|c|c|c|}
\hline 140 & $82.48 \pm 9.67$ & $79.84 \pm 6.60$ & $83.04 \pm 3.92$ & $0.244^{\#}$ \\
\hline 150 & $81.04 \pm 7.9$ & $80.32 \pm 5.7$ & $84.72 \pm 4.23$ & $0.03^{*}$ \\
\hline 160 & $79.84 \pm 6.88$ & $81.24 \pm 3.46$ & $83.16 \pm 6.74$ & $0.14^{\#}$ \\
\hline 170 & $80.72 \pm 6.16$ & $80.16 \pm 6.42$ & $84.8 \pm 8.06$ & $0.041^{*}$ \\
\hline 180 & $80.32 \pm 7.8$ & $79.52 \pm 4.73$ & $82.96 \pm 4.93$ & $0.112^{\#}$ \\
\hline
\end{tabular}

Table 4: MAP variations in the three groups.

\begin{tabular}{|c|c|c|c|c|}
\hline $\begin{array}{c}\text { Time intervals in } \\
\text { minutes }\end{array}$ & $\begin{array}{c}\text { Heart rate in Group R } \\
\text { Mean } \pm \text { SD }\end{array}$ & $\begin{array}{c}\text { Heart rate in Group F } \\
\text { Mean } \pm \text { SD }\end{array}$ & $\begin{array}{c}\text { Heart rate in Group } \\
\text { B Mean } \pm \text { SD }\end{array}$ & p value \\
\hline 0 & $89.36 \pm 11.14$ & $88.4 \pm 7.26$ & $96.08 \pm 7.97$ & $0.0062^{*}$ \\
\hline 10 & $87.68 \pm 10.54$ & $85.88 \pm 9.39$ & $93.6 \pm 9.2$ & $0.0163^{*}$ \\
\hline 20 & $84.48 \pm 8.9$ & $81.92 \pm 8.9$ & $87.76 \pm 8.5$ & $0.0673^{\#}$ \\
\hline 30 & $83.12 \pm 11.04$ & $78.72 \pm 5.7$ & $84.4 \pm 4.65$ & $0.0276^{*}$ \\
\hline 40 & $82.8 \pm 9.2$ & $77.36 \pm 6.8$ & $84 \pm 4.8$ & $0.0036^{*}$ \\
\hline 50 & $82.24 \pm 7.56$ & $78.4 \pm 6.24$ & $83.6 \pm 4.08$ & $0.0106^{*}$ \\
\hline 60 & $80.24 \pm 9.13$ & $77.96 \pm 4.8$ & $84.64 \pm 4.15$ & $0.0017^{*}$ \\
\hline 70 & $76.68 \pm 7.56$ & $76.92 \pm 5.36$ & $83.04 \pm 5.97$ & $0.0046^{*}$ \\
\hline 80 & $81.2 \pm 6.9$ & $77.32 \pm 3.62$ & $83.04 \pm 5.3$ & $0.0015^{*}$ \\
\hline 90 & $80.32 \pm 8.07$ & $79.04 \pm 4.28$ & $84.24 \pm 5.46$ & $0.010^{*}$ \\
\hline 100 & $81.36 \pm 9.65$ & $80.44 \pm 4.89$ & $83.64 \pm 6.71$ & $0.291^{\#}$ \\
\hline 110 & $80.96 \pm 8.02$ & $79.52 \pm 6.03$ & $84.72 \pm 7.7$ & $0.04^{*}$ \\
\hline 120 & $81.84 \pm 7.61$ & $78.72 \pm 6.9$ & $83.92 \pm 5.8$ & $0.03^{*}$ \\
\hline 130 & $81.04 \pm 9.25$ & $79.52 \pm 6.8$ & $84.04 \pm 4.7$ & $0.083^{\#}$ \\
\hline 140 & $82.48 \pm 9.67$ & $79.84 \pm 6.60$ & $83.04 \pm 3.92$ & $0.244^{\#}$ \\
\hline 150 & $81.04 \pm 7.9$ & $80.32 \pm 5.7$ & $84.72 \pm 4.23$ & $0.03^{*}$ \\
\hline 160 & $79.84 \pm 6.88$ & $81.24 \pm 3.46$ & $83.16 \pm 6.74$ & $0.14^{\#}$ \\
\hline 170 & $80.72 \pm 6.16$ & $80.16 \pm 6.42$ & $84.8 \pm 8.06$ & $0.041^{*}$ \\
\hline 180 & $80.32 \pm 7.8$ & $79.52 \pm 4.73$ & $82.96 \pm 4.93$ & $0.112^{\#}$ \\
\hline
\end{tabular}

\section{Discussion}

Ropivacaine, a pure $\mathrm{S}$ enantiomer of bupivacaine and with reduced lipophilicity is associated with lesser central nervous system toxicity and cardiotoxicity. Thus it is less likely to penetrate large myelinated A-beta motor fibers, resulting in a relatively reduced motor blockade ${ }^{[5,9]}$. Hence, we preferred ropivacaine over other local anaesthetics in our study. We used $0.5 \%$ ropivacaine in our study as there is no difference in onset or duration of action between $0.75 \%$ and $0.5 \%$ ropivacaine authenticated by previous studies [9]. Many adjuvants have been used along with local anaesthetics in peripheral nerve blocks. In our study we have compared the effect of fentanyl which is a pure opioid agonist with buprenorphine which is partial agonistantagonist opioid as adjuvant to ropivacaine for ABPB. Buprenorphine is a semi-synthetic derivative of thebaine and a lipophilic opioid with high molecular weight and a $\mu^{-}$receptor partial agonist. It has antagonistic effect on $\delta$ and $\mathrm{K}^{-}$opioid receptors, which explains its less sedative and psychotomimetic effect than morphine or fentanyl. It has a dose- ceiling effect on respiratory depression, but not on analgesia [11, 12]. Receptor binding assays performed to distinguish the opioid binding characteristics of fentanyl and buprenorphine has showed that buprenorphine has a slow receptor association, but high affinity to multiple sites from which dissociation was very slow and incomplete. On the other hand, fentanyl achieves rapid equilibrium and dissociates rapidly and completely ${ }^{[12,14]}$. The strong binding of buprenorphine to the $\mu$-opioid receptor is relatively slow compared with other opioids such as fentanyl [15, 16]. However buprenorphine achieves effective analgesia at relatively low receptor occupancy $(5 \%-10 \%)$. Hence low plasma concentrations of buprenorphine are sufficient to provide effective analgesia. The slow dissociation of buprenorphine from the receptor results in a long duration of effect. There are many supportive studies using buprenorphine as adjuvant to local anaesthetic in brachial plexus which have demonstrated significant prolongation of analgesia, sensory and motor block ${ }^{[9,10,12,16,25]}$.Our study demonstrated a significantly faster onset of sensory and motor block in buprenorphine group which can be explained by its high analgesic potency determined by its high lipid solubility leading to faster penetration of lipid membranes, binding to receptors and hastening of block. Similar results in the onset of sensory block were observed by Behr et al. [19] who studied the effect of adding buprenorphine to levobupivacaine. Patil et al. ${ }^{[20]}$ studied the effect of $3 \mu \mathrm{g} / \mathrm{kg}$ buprenorphine as an adjuvant to a mixture of bupivacaine and lignocaine in supraclavicular block and found no difference in the mean onset of block, but a significant prolongation of motor block, sensory block and analgesia. These studies used buprenorphine with different local anaesthetic agents and the technique and route of block varied in all the studies. There are limited studies comparing the use of ropivacaine with fentanyl to ropivacaine with buprenorphine. Study by Fletcher et al. ${ }^{[21]}$ concluded that there was no benefit of addition of fentanyl to lidocaine with epinephrine for ABPB except for faster block onset along the musculocutaneous nerve trunk. Nishikawa $\mathrm{K}$ et al. demonstrated that fentanyl as an adjuvant to lidocaine in ABPB causes an improved analgesia and sensory effect, but a delayed onset of analgesia as the $\mathrm{pH}$ of lidocaine solution was decreased from 6.2 to 5.2 by the addition of fentanyl ${ }^{[22]}$. Karakaya D et al. found that the addition of $100 \mu \mathrm{gms}$ of fentanyl to $0.25 \%$ bupivacaine in ABPB almost doubled the duration of analgesia when compared to $0.25 \%$ bupivacaine alone ${ }^{[23]}$. Study by Fanelli G et al. showed that the addition of $1 \mu \mathrm{gms} / \mathrm{kg}$ of fentanyl to $0.75 \%$ ropivacaine for ABPB by nerve stimulator failed to improve the block characteristics ${ }^{[24]}$. But in his study the sample size was only 15 which could explain for the results contrary to our study. The faster onset of block with opioid adjuvants may be due 
to action on peripheral opioid receptors. The use of ultrasound can significantly shorten the onset time of ABPB as compared with nerve stimulation guidance using a multiple injection technique and also improved completeness of sensory and motor block [25, 27]. The findings in the present study are in agreement with the observations in a number of studies where addition of fentanyl has been shown to prolong the block characteristics. Though most of the studies showed a prolongation in analgesia with use of adjuvant, the onset time of block varied in the studies. These conflicting results could be attributed to use of different local anesthetic in different concentrations, type of approach for the block and technique of block. We had used ultrasound guidance, but in some studies either peripheral nerve stimulator or a landmark technique was used. In our study, adjuvants to the local anaesthetics used were buprenorphine, which is a lipid soluble opioid agonist- antagonist and fentanyl, which is a pure agonist. Addition of $1 \mathrm{ml}(0.3 \mathrm{mg})$ buprenorphine or 1 $\mathrm{ml}(50 \mu \mathrm{g})$ fentanyl to $30 \mathrm{ml}$ of $0.5 \%$ ropivacaine shortens the onset of sensory and motor block, prolongs the duration of sensory block, motor block and analgesia significantly, without any adverse effects. The analgesia was significantly prolonged with buprenorphine than fentanyl. Thus, buprenorphine can be used as an ideal and safe adjuvant to ropivacaine for ultrasound guided ABPB. The use of ultrasound averts any technique related complications. A limitation of our study was that a larger sample size could have added more precision to our results.

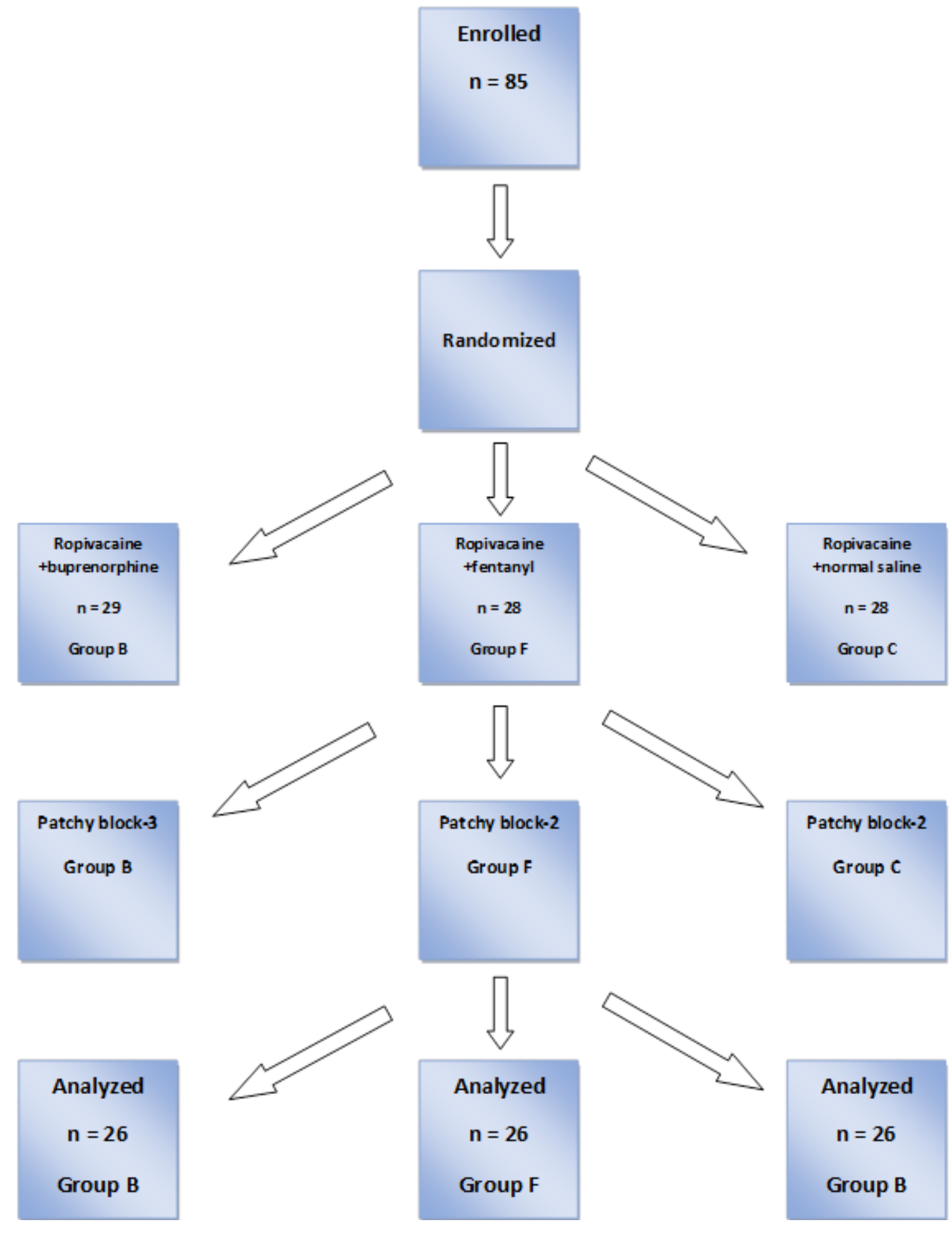


Fig 1: Consort diagram showing flow of participants.

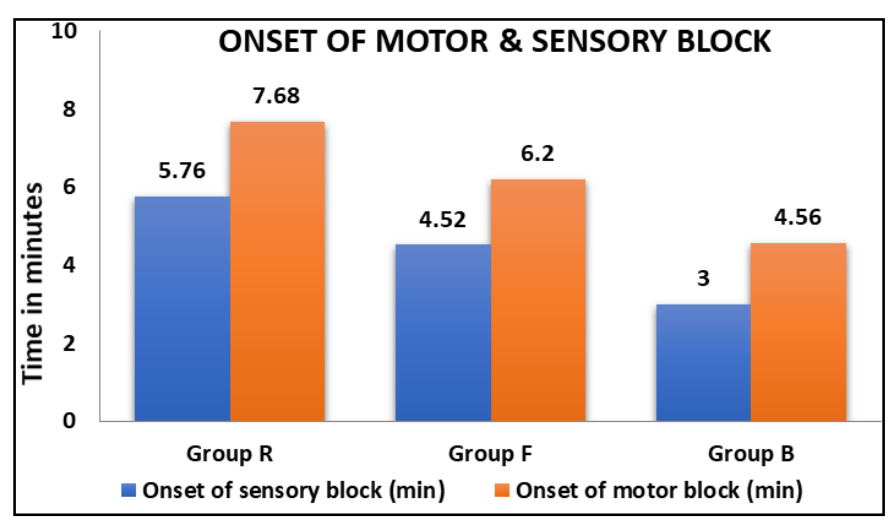

Fig 2: Onset time of motor and sensory block

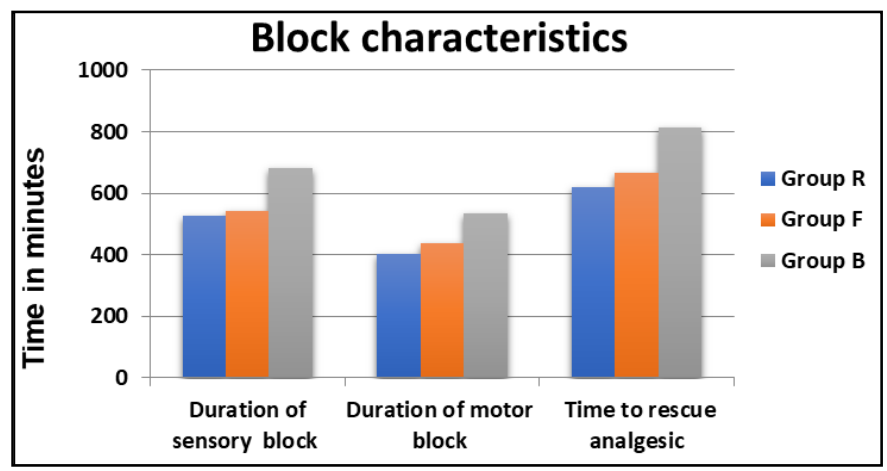

Fig 3: Block characteristics of the three groups.

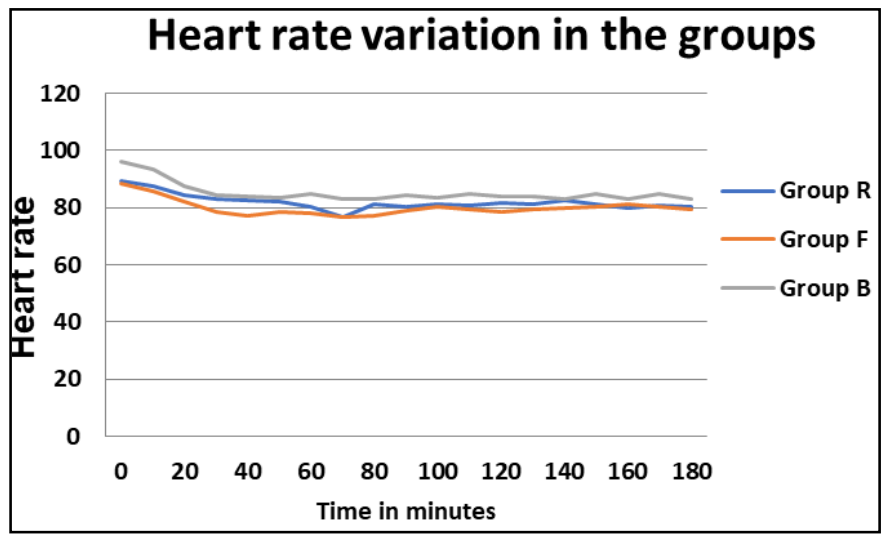

Fig 4: Heart rate variation in the three groups.

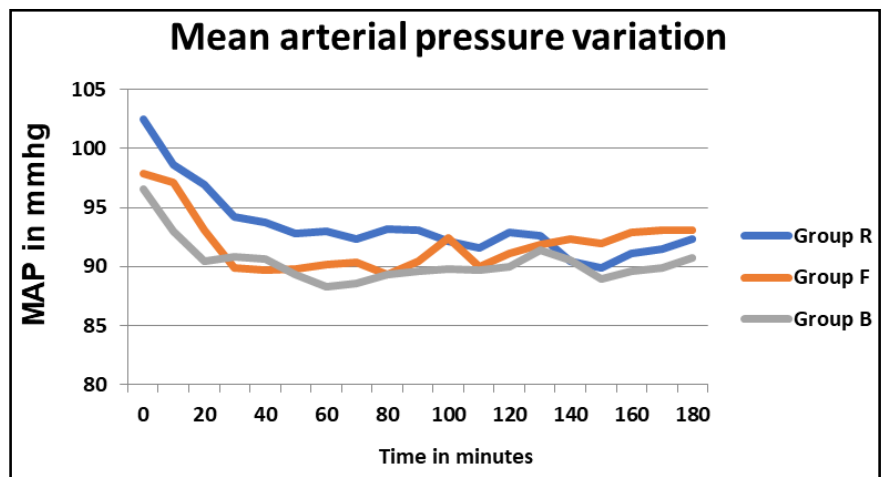

Fig 5: MAP variation in the three groups.

\section{Conclusion}

In our study, adjuvants to the local anaesthetics used were buprenorphine, which is a lipid soluble opioid agonistantagonist and fentanyl, which is a pure agonist. Addition of
$1 \mathrm{ml}(0.3 \mathrm{mg})$ buprenorphine or $1 \mathrm{ml}(50 \mu \mathrm{g})$ fentanyl to 20 $\mathrm{ml}$ of $0.5 \%$ ropivacaine shortens the onset of sensory and motor block, prolongs the duration of sensory block, motor block and analgesia significantly, without any adverse effects. The analgesia was significantly prolonged with buprenorphine than fentanyl. Thus, buprenorphine can be used as an ideal and safe adjuvant to ropivacaine for ultrasound guided ABPB. The use of ultrasound averts any technique related complications.

\section{Financial support and sponsorship-none Conflict of interest-none}

\section{References}

1. Borgeat A. All roads do not lead to Rome. Anesthesiology. 2006; 105:1-2.

2. Kulenkampff D. Brachial plexus anaesthesia: Its indications, technique, and dangers. Ann Surg. 1928; 87:883-91

3. Satapathy AR, Coventry DM. Axillary brachial plexus block. Anesthesiol Res Pract. 2011; 2011:173796.

4. Richman JM, Liu SS, Courpas G, Wong R, Rowlingson AJ, McGready J et al. Does continuous peripheral nerve block provide superior pain control to opioids? A metaanalysis Anesth Analg. 2006; 102:248-57.

5. Akerman B, Hellberg IB, Trossvik C. Primary evaluation of the local anaesthetic properties of the amino amide agent ropivacaine (LEA 103). Acta Anaesthesiol Scand. 1988; 32:571-8.

6. McClellan KJ, Faulds D. Ropivacaine: an update of its use in regional anaesthesia. Drugs. 2000; 60:1065-93.

7. Brummett CM, Williams BA. Additives to local anesthetics for peripheral nerve blockade. Int Anesthesiol Clin. 2011; 49:104-16.

8. Stein C. Peripheral mechanisms of opioid analgesia. Anesth Analg. 1993; 76:182-91.

9. Klein SM, Greengrass RA, Steele SM, D'Ercole FJ, Speer KP, Gleason DH et al. A comparison of $0.5 \%$ bupivacaine, $0.5 \%$ ropivacaine, and $0.75 \%$ ropivacaine for interscalene brachial plexus block. Anesth Analg. 1998; 87:1316-9.

10. Candido KD, Franco CD, Khan MA, Winnie AP, Raja DS. Buprenorphine added to the local anesthetic for brachial plexus block to provide postoperative analgesia in outpatients. Reg Anesth Pain Med. 2001; 4:352-6

11. Koppert W, Ihmsen H, Körber N, Wehrfritz A, Sittl R, Schmelz M et al. Different profiles of buprenorphineinduced analgesia and antihyperalgesia in a human pain model. Pain. 2005; 118:15-22.

12. Murphy DB, McCartney CJ, Chan VW. Novel analgesic adjuncts for brachial plexus block: A systematic review. Anesth Analg. 2000; 90(5):1122-8.

13. Cooper GM, Paterson JL, Ward ID, Hall GM. Fentanyl and the metabolic response to gastric surgery. Anaesthesia. 1981; 36:667-71.

14. Boas RA, Villiger JW. Clinical Actions of Fentanyl and Buprenorphine: The Significance of Receptor Binding. Br J Anaesth. 1985; 57:192-6.

15. Bickel WK, Stitzer ML, Bigelow GE, Liebson IA, Jasinski DR, Johnson RE et al. Buprenorphine: doserelated blockade of opioid challenge effects in opioid dependent humans. J Pharmacol. Exp. Ther. 1988; 
247:47-53.

16. Viel EJ, Eledjam JJ, De La, Coussaye JE, D'Athis F. Brachial plexus block with opioids for postoperative pain relief: Comparison between buprenorphine and morphine. Reg Anesth. 1989; 14:274-8.

17. Bazin JE, Massoni C, Bruelle P, Fenies V, Groslier D, Schoeffler $\mathrm{P}$ et al. The addition of opioids to local anaesthetics in brachial plexus block: The comparative effects of morphine, buprenorphine and sufentanil. Anaesthesia. 1997; 52:858-62.

18. Jadon A, Panigrahi M, Parida S, Chakraborty S, Agrawal P, Panda A et al. Buprenorphine improves the efficacy of bupivacaine in nerve plexus block: A double blind randomized evaluation in subclavian perivascular brachial block. The Internet Journal of Anaesthesiology. 2008; 16:2.

19. Behr A, Freo U, Ori C, Westermann B, Alemanno F. Buprenorphine added to levobupivacaine enhances postoperative analgesia of middle interscalene brachial plexus block. J Anesth. 2012; 26:746-51.

20. Patil S, Debata D, Doshi C, Vyas V, Sinha S. Effect of buprenorphine as an adjunct with plain local anesthetic solution in supraclavicular brachial plexus block on quality and duration of postoperative analgesia. J Anaesthesiol Clin Pharmacol. 2015; 31:496-500.

21. Fletcher D, Kuhlman G, Samii K. Addition of fentanyl to $1.5 \%$ lidocaine does not increase the success of axillary plexus block. Reg Anesth. 1994; 19:183-8.

22. Nishikawa K, Kanaya N, Nakayama M, Igarashi M, Tsunoda K, Namiki A. Fentanyl improves analgesia but prolongs the onset of axillary brachial plexus block by peripheral mechanism. Anesth Analg. 2000; 91:384-7.

23. Karakaya D, B“uy"ukg“oz F, Baris S, G"uldo־gus F, T"ur A. Addition of fentanyl to bupivacaine prolongs anesthesia and analgesia in axillary brachial plexus block. Reg Anesthes Pain Med. 2001; 26:434-8.

24. Fanelli G, Casati A, Magistris L, Berti M, Albertin A, Scarioni $\mathrm{M}$ et al. Fentanyl does not improve the nerve block characteristics of axillary brachial plexus anaesthesia performed with ropivacaine. Acta Anaesthesiol Scand. 2001; 45:590-4.

25. Casati A, Danelli G, Baciarello M, Corradi M, Leone S, Di Cianni $\mathrm{S}$ et al. A prospective, randomized comparison between ultrasound and nerve stimulation guidance for multiple injection axillary brachial plexus block. Anesthesiology. 2007; 106:992-9.

26. Marhofer P, Sitzwohl C, Greher M, Kapral S. Ultrasound guidance for infraclavicular brachial plexus anaesthesia in children. Anaesthesia. 2004; 59:642-6.

27. Soeding PE, Sha S, Royse CE, Marks P, Hoy G, Royse AG et al. A randomized trial of ultrasound-guided brachial plexus anaesthesia in upper limb surgery. Anaesth Intensive Care. 2005; 33:719-25. 